Check for updates

Cite this: RSC Adv., 2019, 9, 31960

Received 4th April 2019

Accepted 3rd October 2019

DOI: $10.1039 / c 9 r a 02538 c$

rsc.li/rsc-advances

\section{Catalytic fast pyrolysis of lignin to produce aromatic hydrocarbons: optimal conditions and reaction mechanism}

\author{
Zhongyang Luo, (D) * Kongyu Lu, Yi Yang, Simin Li and Guoxiang Li
}

Catalytic fast pyrolysis of lignin with zeolite catalysts is a promising method to produce aromatic hydrocarbons. In this paper, alkali lignin was used as a model compound to pyrolyze with HZSM-5 (silica to alumina ratio, SAR = 23), HZSM-5(50), HZSM-5(80), HY and H . Non-condensable vapours and condensable fractions were determined and quantified by GC/FID and GC/MS respectively. 7.63 wt\% of aromatic hydrocarbons and $3.34 \mathrm{wt} \%$ of $\mathrm{C} 1-\mathrm{C} 4$ alkanes and alkenes were acquired. The effects of catalysts and pyrolysis parameters were studied in this work. Different reaction pathways were compared and discussed by combining density functional theory (DFT) calculations. Cyclization reactions to form aromatic hydrocarbons were thought to be the main reaction pathway, while direct demethylation, demethoxylation and dehydration reactions were the secondary reaction pathway to convert phenolic lignin monomers to non-oxygenated aromatic hydrocarbons.

\section{Introduction}

BTEX (benzene, toluene, ethyl benzene and xylenes), four monocyclic aromatic hydrocarbons (MAH), are important petrochemical materials in manufacturing numerous organic chemicals, such as plastic resins, synthetic fibres, solvents and plasticizers. $^{2}$ Polycyclic aromatic hydrocarbons (PAH), for instance naphthalene and anthracene, are used as additives to jet fuel. Nowadays, MAH and PAH are mainly obtained from fossil petroleum. Catalytic fast pyrolysis of lignocellulosic biomass with some zeolite catalysts has been proved to be a renewable approach to produce aromatic hydrocarbons. ${ }^{1,3}$

Lignocellulosic biomass mainly consists of cellulose, hemicellulose and lignin. Cellulose and hemicellulose are typical carbohydrates, while lignin is an aromatic polymer. The monomers of lignin are mainly $p$-coumaryl, coniferyl and sinapyl alcohols. ${ }^{4}$ (Fig. 1) Therefore, lignin is often designated as H-lignin (p-hydroxyphenyl subunits), G-lignin (guaiacyl subunits) or S-lignin (syringyl subunits). Because of the aromatic structure of lignin itself, catalytic pyrolysis of lignin should achieve a higher aromatic hydrocarbon yield than cellulose and hemicellulose theoretically. However, some previous works showed contrary results that cellulose and hemicellulose could have a higher aromatic hydrocarbon yield than lignin.,

As shown in Fig. 2, the whole process of lignin catalytic fast pyrolysis with zeolite catalysts could be divided into mainly two steps. Firstly, feedstock was thermally decomposed into smaller

State Key Laboratory of Clean Energy Utilization, Zhejiang University, Hangzhou 310027, China. E-mail: zyluo@zju.edu.cn; Tel: +86-571-87952440 oxygenated molecules, such as acids, aldehydes, furans, phenols, anhydrosugars and so on. ${ }^{7,8}$ All these intermediate products then diffused into zeolite pores. Disagreements aroused here. G. W. Huber-12 believed that these intermediate oxygenates would be deoxygenated firstly due to the acid sites on zeolites to form dehydrate species like ethylene, propylene, butylene and so on. The dehydrate species were called hydrocarbon pool. These $\mathrm{C} 2-\mathrm{C} 4$ dehydrate products would go through a route from olefin to aromatics, to form the aromatic hydrocarbons (Fig. 2 route 1). However, others ${ }^{13,14}$ believed phenol, guaiacol and other aromatic oxygenates to be the intermediate products. After demethoxylation reactions and demethylation reactions with catalysts, these phenolic were converted to phenol, cresol and ethylphenol. ${ }^{15}$ Finally, after dehydration reaction, benzene, toluene, xylene were acquired (Fig. 2 route 2).<smiles>C#CCCCCCCO</smiles><smiles>COc1cc(/C=C/CO)ccc1O</smiles>

Fig. 1 Three lignin monomers. 


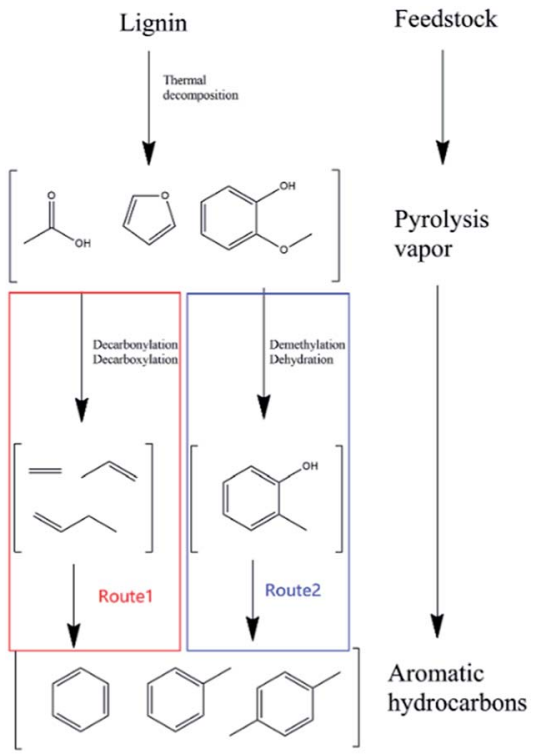

Fig. 2 Different reaction pathways for lignin catalytic fast pyrolysis.

In order to achieve higher aromatic hydrocarbons yield in catalytic fast pyrolysis of lignin, it is very important to figure out the optimal pyrolysis parameters and illustrate the reaction mechanism. In this paper, catalytic pyrolysis of lignin with five different zeolite catalysts were compared. Influences of catalysts, catalyst to lignin ratio (CLR), heating rate, pyrolysis temperature on both aromatic hydrocarbons and C1-C4 gaseous hydrocarbon were studied. Different reaction pathways were compared and discussed by combining density functional theory (DFT).

\section{Experimental setup}

\subsection{Feedstock}

Alkali lignin, an important by-product of pulp and paper industry, was commonly used as a model compound of lignin. ${ }^{16,17}$ In this work, alkali lignin (low sulfonate content, Sigma Aldrich, USA) was used as pyrolysis feedstock. Ultimate analysis and industrial analysis of the raw material have been carried out in previous work. ${ }^{17}$ The ultimate analysis result (ash free) of alkali lignin was presenting as $\mathrm{C}$ of $62.46 \%, \mathrm{H}$ of $3.72 \%$, $\mathrm{O}$ of $32.37 \%$, $\mathrm{N}$ of $0.26 \%$, and $\mathrm{S}$ of $1.19 \%$. The proximate analysis result (dry basis) of alkali lignin was presenting as volatiles of $64.66 \%$, fixed carbon of $32.47 \%$, and ash of $2.87 \%$. Prior to the experiment, alkali lignin was dried at $105{ }^{\circ} \mathrm{C}$ for more than $4 \mathrm{~h}$ to remove moisture.

\subsection{Catalysts preparation and characterization}

HZSM-5(23), HZSM-5(50), HZSM-5(80), HY, H $\beta$, purchased from Tianjin Nankai catalyst company, were used as catalysts in these catalytic pyrolysis experiments. Prior to all experiments and characterization, all catalysts were dried at $120^{\circ} \mathrm{C}$ for $16 \mathrm{~h}$.

To obtain surface area and pore size distribution of the catalysts, nitrogen adsorption/desorption isotherms were acquired from a chemical station (Micromeritics ASAP-2010). All samples were degassed in vacuum at $220{ }^{\circ} \mathrm{C}$ over 24 hours before physisorption. The surface areas were derived from a standard Brunauer-Emmett-Teller (BET) equation. The average pore diameters were calculated using Barret-JoynerHalenda (BJH) analysis. ${ }^{18}$

To compare the acidity of HZSM-5 with different silicon to aluminium ratio (SAR), temperature programmed desorption of ammonia ( $\mathrm{NH}_{3}$-TPD) was performed in an AutoChem II 2910 with a mass spectrometry (MS). In a typical run, after degassing

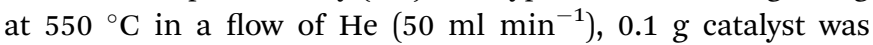
exposed in a flow of $\mathrm{NH}_{3}\left(15 \% \mathrm{NH}_{3}+85 \% \mathrm{He}, 50 \mathrm{ml} \mathrm{min}{ }^{-1}\right)$ at $60{ }^{\circ} \mathrm{C}$ for 1 hour. After that, to remove the physically absorbed $\mathrm{NH}_{3}$, the catalyst sample was flushed by $\mathrm{He}\left(50 \mathrm{~mL} \mathrm{~min}{ }^{-1}\right)$ at $100{ }^{\circ} \mathrm{C}$ for 2 hours. Then the sample was heated up to $700{ }^{\circ} \mathrm{C}$ $\left(10^{\circ} \mathrm{C} \min ^{-1}\right)$. The amount of chemical adsorbed $\mathrm{NH}_{3}$ was recorded by $\mathrm{MS}{ }^{19}$

\subsection{Catalytic pyrolysis procedure and products analysis}

2.3.1 Catalytic pyrolysis of lignin. Experiments were carried out by a microscale pyrolysis unit, CDS Pyroprobe 5250 (CDS Analytical Inc., USA), which was able to control the pyrolysis parameters (heating rate, pyrolysis temperature, resident time). The structure of the Pyroprobe was shown in Fig. 3. For noncatalytic pyrolysis experiments, about $0.50 \mathrm{mg}$ of alkali lignin was placed between quartz wool in a quartz tube. For catalytic pyrolysis experiments, catalysts and alkali lignin were premixed at a certain mass ratio. A certain amount of the mixture was placed between quartz wool to ensure approximately $0.50 \mathrm{mg}$ alkali lignin to be pyrolyzed. For each sample, five or more replicates were done. Pyrolysis proceeded by setting the Pyroprobe at $600{ }^{\circ} \mathrm{C}$ at a heating rate of maximum $10000 \mathrm{~K} \mathrm{~s}^{-1}$. The heating wire would heat up the quartz tube, thus lignin would pyrolyze. To ensure that all the reactions took place thoroughly, a hold time of $30 \mathrm{~s}$ was set. During the reaction, a stream of 20 $\mathrm{ml} \mathrm{min}^{-1}$ helium was used as carrier gas to purge out both noncondensable gases and condensable fractions. A trap setting at $40{ }^{\circ} \mathrm{C}$ was designed to separate non-condensable gases and condensable fractions. Non-condensable gases were directly purged through the trap to a GC-FID, while condensable fractions were captured by the trap. Then the trap was heated up, condensable fractions were purged into GC-MS by carrier gas for identification.

2.3.2 Condensable fractions. Condensable fractions were separated and identified by a GC-MS (Thermal Fisher TRACE2000-DSQII, USA).The GC used a HP-5 column (Agilent, USA). A detailed temperature control program was the same as our previous study. ${ }^{19}$

In this study, C6-C10 + $\mathrm{PAH}$ were identified and quantified (C6-benzene; C7-toluene; C8-xylene, ethyl benzene; C9-trimethyl

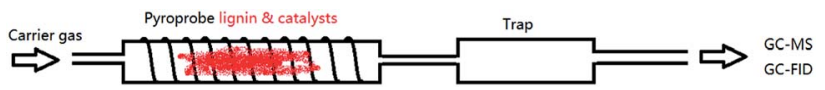

Fig. 3 Diagram of CDS 5250 Pyroprobe connected with GC-MS and GC-FID. 
benzene, methyl ethyl benzene, indane, indene; $\mathrm{C} 10+\mathrm{PAH}-$ naphthalene, methylnaphthalene, anthracene, phenanthrene). Identification of products was to compare the mass spectra of the peaks with NIST library (version 2014). Pure compounds (Sigma Aldrich, USA) of aromatic hydrocarbons mentioned above were used to conduct the quantification by external standards with a five-point calibration curve.

2.3.3 Non-condensable gases. Non-condensable gases were separated and identified by a 7890A GC-FID (Agilent, USA). Gases were separated in the column. Then alkanes and alkenes from pyrolysis reactions and catalytic reactions were detected by FID. Pure standard gases were used to confirm all the alkanes and alkenes. Quantification of alkanes and alkenes was performed using external standards by a five-point calibration curve.

\subsection{Calculation of pyrolysis reactions and catalytic reactions}

In order to figure out the mechanism of catalytic pyrolysis of lignin, some calculation was carried out using the Gaussian 03 suite of program. 1-(3,5-dimethoxyphenyl)-2-(2-methoxyphenoxy) propane-1,3-diol (DMPD, Fig. 4), a typical $\beta$-o-4 ether linkage lignin dimer, contains a G-lignin monomer and a S-lignin monomer. ${ }^{20}$ In this calculation part, DMPD was designed as the initial lignin dimer to compare the route1 and route 2 reaction pathways. The equilibrium geometries of reactants, intermediates, transition states, and products were optimized using density functional theory (DFT) methods employing B3LYP/6-31G(d), and then single point energies were evaluated with a larger 6$311++\mathrm{G}(\mathrm{d}, \mathrm{p})$ basis set at the same level of theory. The transition states were located by the TS method and were confirmed by visual inspection of the imaginary frequency using Gauss view and by performing intrinsic reaction coordinate (IRC) calculations. The reactants, intermediates, and products had no imaginary frequencies, whereas each transition state had only one imaginary frequency. Activation energies (the reaction energy barriers) of reaction were estimated based on the energy difference, including the zero-point energy correction, between the transition state and the reactant. For free-radical reactions, the bond dissociation energies were employed as approximations of the activation energies.

\section{Results and discussion}

\subsection{Catalyst properties}

Table 1 shows the comparison of nitrogen adsorption/ desorption properties of the catalysts used in this paper.

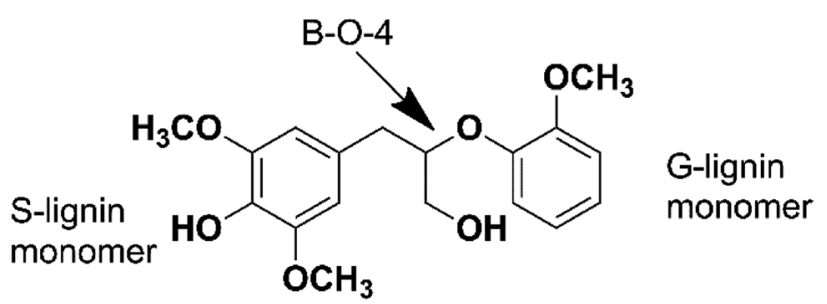

Fig. 4 Structure of 1-(3,5-dimethoxyphenyl)-2-(2-methoxyphenoxy) propane-1,3-diol.
Table 1 Structure properties of the catalysts by nitrogen adsorption/ desorption

\begin{tabular}{llll}
\hline Catalyst & $\begin{array}{l}\text { BET Surface } \\
\text { area }\left(\mathrm{m}^{2} \mathrm{~g}^{-1}\right)\end{array}$ & $\begin{array}{l}\text { Pore size } \\
(\mathrm{nm})\end{array}$ & $\begin{array}{l}\text { Pore volume } \\
\left(\mathrm{cm}^{3} \mathrm{~g}^{-1}\right)\end{array}$ \\
\hline HZSM-(23) & 357.74 & 0.501 & 0.184 \\
HZSM-(50) & 315.08 & 0.498 & 0.157 \\
HZSM-(80) & 259.71 & 0.510 & 0.132 \\
HY & 660.42 & 0.511 & 0.338 \\
H $\beta$ & 527.31 & 0.767 & 0.405
\end{tabular}

HZSM-5, as typical microporous catalysts, had an average pore size from 0.498-0.510 $\mathrm{nm}$ with different SAR. The BET surface area and the pore volume of different HZSM-5 decreased from $357.74 \mathrm{~m}^{2} \mathrm{~g}^{-1}$ to $259.71 \mathrm{~m}^{2} \mathrm{~g}^{-1}$ and $0.184 \mathrm{~cm}^{3} \mathrm{~g}^{-1}$ to $0.132 \mathrm{~cm}^{3}$ $\mathrm{g}^{-1}$ respectively, with the increase of SAR. It implied that, with a higher SAR, the reaction activities of HZSM-5 decreased. HY had a similar pore size as HZSM-5 of $0.511 \mathrm{~nm}$, a larger surface area of $660.422 \mathrm{~m}^{2} \mathrm{~g}^{-1}$ and a larger pore volume of $0.338 \mathrm{~cm}^{3}$ $\mathrm{g}^{-1}$. H $\beta$ had the largest pore size and pore volume among all the five zeolite catalysts. The pore size of three HZSM-5 catalysts and HY were similar to MAHs, which might promote the cyclization reactions (route1). On the other hand, $\mathrm{H} \beta$ with a pore size of $0.767 \mathrm{~nm}$ might be suitable for demethoxylation reactions and demethylation reactions to convert phenolic oxygenates to aromatic hydrocarbons (route2).

Fig. 5 showed the $\mathrm{NH}_{3}$ desorption amounts of HZSM-5 catalysts with different $\mathrm{SAR}$ in $\mathrm{NH}_{3}$-TPD. The $\mathrm{NH}_{3}$ desorption curves illustrated the strength and amount of acid. The curves of three HZSM-5 all had a peak located around $200{ }^{\circ} \mathrm{C}$, which represented weak acid sites. Another peak related to strong acid sites was about $370{ }^{\circ} \mathrm{C}$. With the increase of SAR, the amount and strength of acid sites from HZSM-5 catalyst decrease obviously, which results in the decrease of peak height, peak area and the shift of peak point to low temperature. This phenomenon has been reported in many literatures related to HZSM-5 catalysts.

\subsection{Influence of catalyst}

3.2.1 Comparison between catalytic pyrolysis and noncatalytic pyrolysis. Table 2 illustrated the condensable

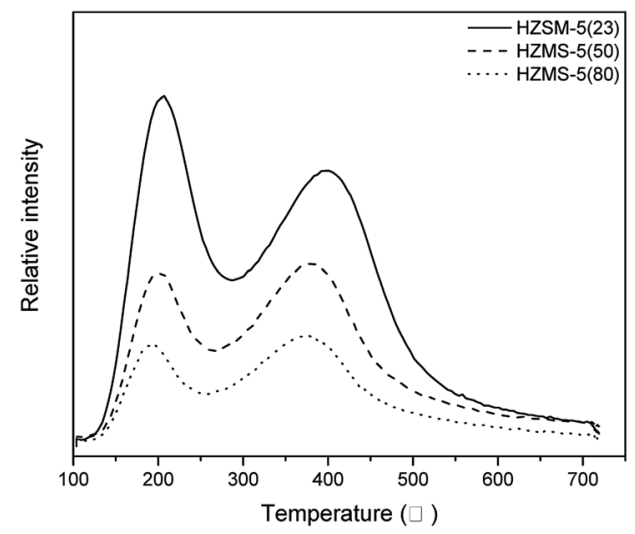

Fig. $5 \mathrm{NH}_{3}$ desorption amount of $\mathrm{HZSM}-5(23,50,80) \mathrm{NH}_{3}-\mathrm{TPD}$. 
Table 2 Condensable fractions distribution comparison between non-catalytic pyrolysis and catalytic pyrolysis

\begin{tabular}{lll}
\hline Category & Non-catalytic $^{a}$ & Catalytic $^{b}$ \\
\hline Acid & $7.31 \%^{c}$ & N/A \\
Furan & $11.39 \%$ & N/A \\
Sugar & $2.42 \%$ & N/A \\
Phenol & $68 \%$ & N/A \\
MAHs & N/A & $64.23 \%$ \\
PAHs & $3.31 \%$ & $31.53 \%$
\end{tabular}

${ }^{a}$ Non-catalytic: direct pyrolysis of lignin, pyrolysis temperature $600{ }^{\circ} \mathrm{C}$, heating rate $10000 \mathrm{~K} \mathrm{~s}^{-1}$, resident time $30 \mathrm{~s} .{ }^{b}$ Catalytic: catalytic pyrolysis of lignin with HZSM-5(23), lignin to catalyst ratio $1: 5$, pyrolysis temperature $600{ }^{\circ} \mathrm{C}$, heating rate $10000 \mathrm{~K} \mathrm{~s}^{-1}$, resident time $30 \mathrm{~s}^{c}{ }^{c}$ Based on relative peak area percentage in GC-MS spectra. ${ }^{d} \mathrm{~N} /$ A: not detected.

fractions distribution comparison between non-catalytic and catalytic pyrolysis of lignin with HZSM-5(23). The main condensable fractions of non-catalytic pyrolysis were acetic acid (acid), furfural, HMF, (furan), phenol, guaiacol, cresol, dimethyl phenol, ethyl phenol, (phenol) and levoglucosan (sugar). Only a few naphthalene and methylnaphthalene (PAH) could be detected. None MAH could be detected. The results were similar to previous study. ${ }^{21}$ However, with the existence of catalyst, the condensable fractions were completely different from noncatalytic pyrolysis. The main products became benzene, toluene, ethylbenzene, xylene, trimethyl benzene, indane, indene, (MAHs) naphthalene and methylnaphthalene (PAHs). The completely different results showed that the catalytic pyrolysis of lignin had the potential to produce both MAH and $\mathrm{PAH}{ }^{22}$

3.2.2 Comparison between different catalysts. In this section, to compare the effect of different catalysts, $0.5 \mathrm{mg}$ lignin was mixed with five different catalysts $(2.5 \mathrm{mg})$ respectively and pyrolyzed at $600{ }^{\circ} \mathrm{C}$ at a heating rate of $10000 \mathrm{~K} \mathrm{~s}^{-1}$.

HZSM-5, HY, H $\beta$ are zeolite catalysts with some acid sites and have high activity in deoxygenation reaction. As shown in Fig. 6, deoxygenation reactions produced mainly alkanes and

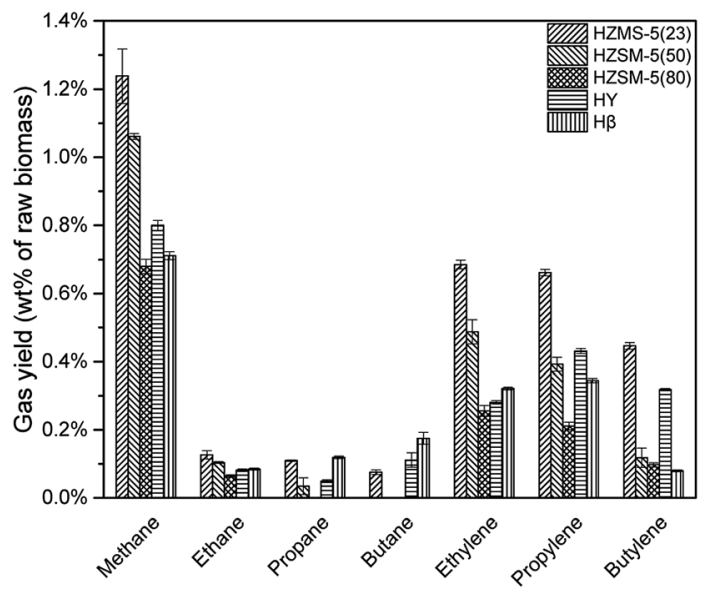

Fig. 6 None-condensable gases from catalytic pyrolysis with different catalysts.

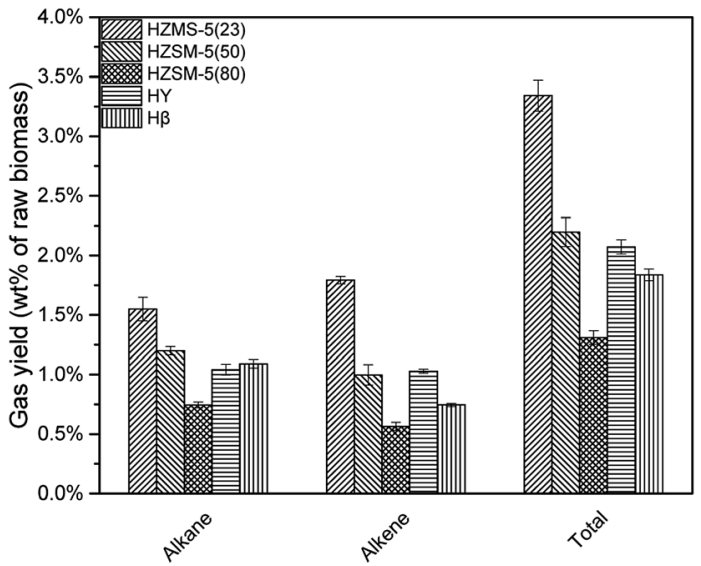

Fig. 7 Hydrocarbon gas yield of catalytic pyrolysis with different catalysts.

alkenes. Methane had the highest yield due to the demethoxyl reactions from $\mathrm{G}$ and $\mathrm{S}$ type lignin monomers. $\mathrm{HY}$ tended not to break $\mathrm{C}-\mathrm{C}$ bond, which resulted in a higher selectivity of propylene and butylene when compared to the other catalysts. Comparatively, HZSM-5(23), with the strongest acid sites among three HZSM-5 type catalysts, produced the most alkanes and alkenes (Fig. 7).

According to Fig. 8, all these five catalysts produced different amount of MAH and PAH in condensable fractions. HY had the lowest reaction activity for aromatic hydrocarbon production. From $\mathrm{C} 7$ to $\mathrm{C} 10+\mathrm{PAH}, \mathrm{HY}$ all had the lowest yield. HZSM-5(23) achieved all the highest yield from $\mathrm{C} 6$ to $\mathrm{C} 10+\mathrm{PAH}$, due to both its strong acid sites and high selectivity in aromatic production reaction. With the increase of HZSM-5 SAR, the yields for MAH and PAH both decreased significantly. HZSM-5 (23) had strongest acidity, which results in higher yield of alkanes and alkenes. Further conversion of these alkanes and alkenes under suitable conditions was able to produce more MAHs by polymerization and cyclization reactions. Fig. 9 showed the

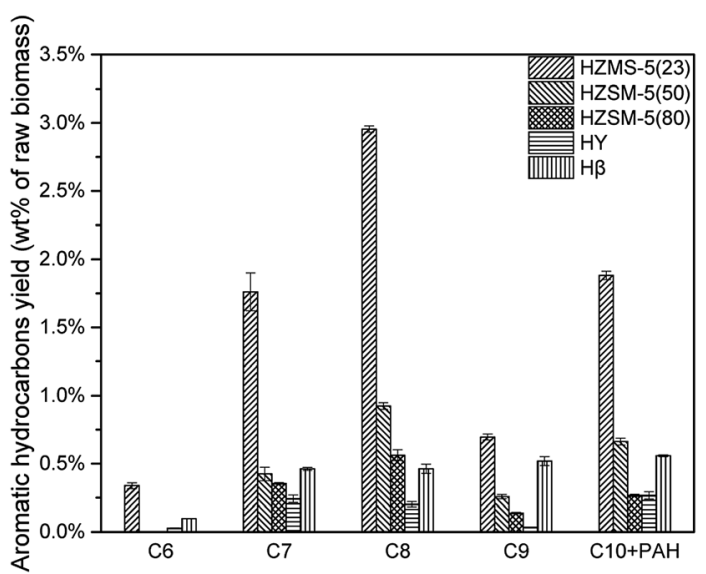

Fig. 8 Aromatic hydrocarbon yields of catalytic pyrolysis with different catalysts (C6-benzene; C7-toluene; C8-xylene, ethyl benzene; C9trimethyl benzene, methyl ethyl benzene, indane, indene; $\mathrm{C} 10+\mathrm{PAH}-$ naphthalene, methylnaphthalene, anthracene, phenanthrene.). 


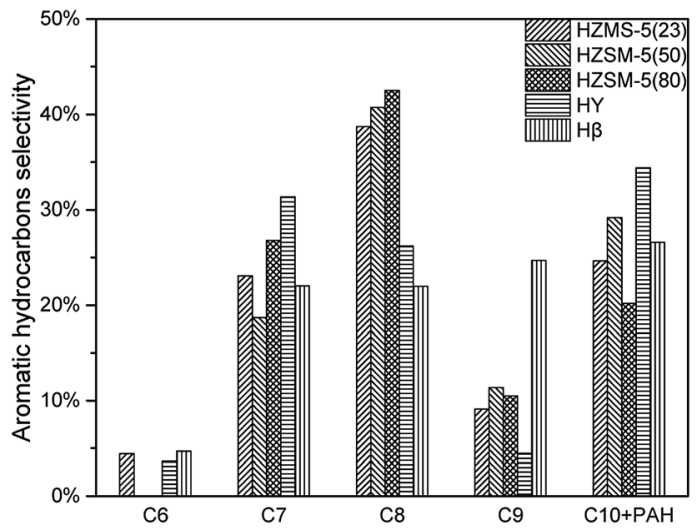

Fig. 9 Aromatic hydrocarbon selectivity of catalytic pyrolysis with different catalysts.

selectivity from C6 to C10 + PAH. HZSM-5 series catalysts produced lots of MAHs such as $\mathrm{C} 7$ and $\mathrm{C} 8$. When the carbon chain continued to increase, HZSM-5 tended to produce more $\mathrm{C} 10+\mathrm{PAH}$ rather than $\mathrm{C} 9$. For $\mathrm{H} \beta$, the selectivity of $\mathrm{C} 6$ to $\mathrm{C} 10+$ PAH was similar due to its relatively large pore size. In total, HZSM-5(23) produced 5.75\% MAH and 1.88\% PAH respectively.(Table 3)

3.2.3 Influence of catalyst to lignin ratio (CLR). In this section, $0.5 \mathrm{mg}$ lignin was mixed with HZSM-5(23) with three different mass ratio $5: 1,1: 1,1: 5$. Then the mixture was pyrolyzed by the Pyroprobe at $600{ }^{\circ} \mathrm{C}$ with a heating rate of $10000 \mathrm{~K} \mathrm{~s}^{-1}$ and a resident time of $30 \mathrm{~s}$.

As shown in Fig. 10, with the decrease of CLR, fewer alkenes were produced due to fewer acid sites. However, when CLR decreased from $1: 1$ to $1: 5$, the yields of methane and ethane increased slightly. The reason was not clear but possible explanation might be easier diffusion of gases and fewer coke formation with less catalyst. When CLR decreased from $5: 1$ to $1: 1$, total hydrocarbon gas yield decreased from $3.34 \mathrm{wt} \%$ to 0.88 wt $\%$, as shown in Table 4 .

The decrease of CLR resulted in less deoxygenation reaction and less aromatic hydrocarbon formation (Fig. 11), and all the aromatic hydrocarbon yields decreased. On the other hand, MAHs and alkenes were thought to be precursors of $\mathrm{C} 10+\mathrm{PAH}$. With a lower CLR, the unstable intermediate products were more dispersed. Thus, the intermediate products were less possible to react with each other to increase the carbon chain, which implied that the increasing of carbon chain became more

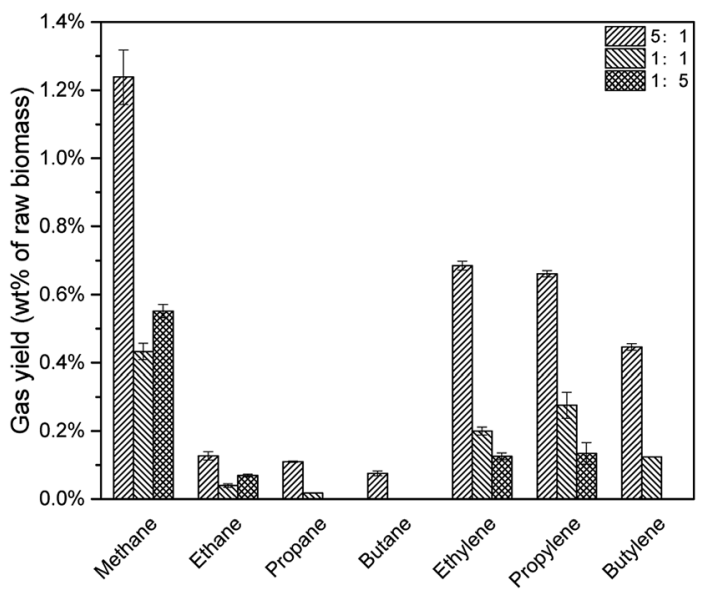

Fig. 10 None-condensable gases from catalytic pyrolysis with different CLR.

Table 4 Hydrocarbon gas yield of catalytic pyrolysis with different CLR

\begin{tabular}{llll}
\hline $\begin{array}{l}\text { Catalyst to } \\
\text { lignin ratio }\end{array}$ & $\begin{array}{l}\text { Alkane } \\
\text { yield }\end{array}$ & $\begin{array}{l}\text { Alkene } \\
\text { yield }\end{array}$ & Total \\
\hline $5: 1$ & $1.55 \%$ & $1.79 \%$ & $3.34 \%$ \\
$1: 1$ & $0.49 \%$ & $0.60 \%$ & $1.09 \%$ \\
$1: 5$ & $0.62 \%$ & $0.26 \%$ & $0.88 \%$
\end{tabular}

difficult with the decrease of CLR. The evidence was that, as shown in Fig. 12, the selectivity peak shifted from $\mathrm{C} 10+\mathrm{PAH}$ to C8, with the decrease of CLR. $5: 1$ had a highest selectivity on $\mathrm{C} 10+\mathrm{PAH}$, while $1: 1$ and $1: 5$ had the highest on C9 and C8 respectively. Due to the less possibility of carbon chain increasing, MAH selectivity increased from $75.34 \%$ to $82.97 \%$ with the decrease of CLR. While the PAH selectivity decreased from $24.66 \%$ to $17.03 \%$.(Table 5 )

\subsection{Influence of pyrolysis parameter}

3.3.1 Influence of pyrolysis temperature. In this section, $0.5 \mathrm{mg}$ lignin was mixed with $2.5 \mathrm{mg}$ HZSM-5(23). Then the mixture was pyrolyzed by the Pyroprobe with a heating rate of $10000 \mathrm{~K} \mathrm{~s}^{-1}$ at different temperature range from $450-700{ }^{\circ} \mathrm{C}$.

As shown in Fig. 13, with the pyrolysis temperature increased, feedstock was decomposed vigorously to produce

Table 3 Aromatic hydrocarbon yields and selectivity of catalytic pyrolysis with different catalysts

\begin{tabular}{|c|c|c|c|c|c|}
\hline Catalyst & MAH yield & PAH yield & Total yield & MAH selectivity $^{b}$ & PAH selectivity $^{c}$ \\
\hline HZMS-(23) & $5.75^{a} \%$ & $1.88 \%$ & $7.63 \%$ & $75.34 \%$ & $24.66 \%$ \\
\hline HZSM-(50) & $1.61 \%$ & $0.66 \%$ & $2.27 \%$ & $70.81 \%$ & $29.19 \%$ \\
\hline HZSM-(80) & $1.06 \%$ & $0.27 \%$ & $1.32 \%$ & $79.82 \%$ & $20.18 \%$ \\
\hline HY & $0.51 \%$ & $0.27 \%$ & $0.77 \%$ & $65.61 \%$ & $34.39 \%$ \\
\hline $\mathrm{H} \beta$ & $1.54 \%$ & $0.56 \%$ & $2.10 \%$ & $73.40 \%$ & $26.60 \%$ \\
\hline
\end{tabular}

${ }^{a}$ Weight percent of raw alkali lignin. ${ }^{b}$ MAH selectivity $=$ MAH yield/(MAH yield + PAH yield). ${ }^{c}$ PAH selectivity $=\mathrm{PAH}$ yield $/(\mathrm{MAH}$ yield $+\mathrm{PAH}$ yield $)$. 


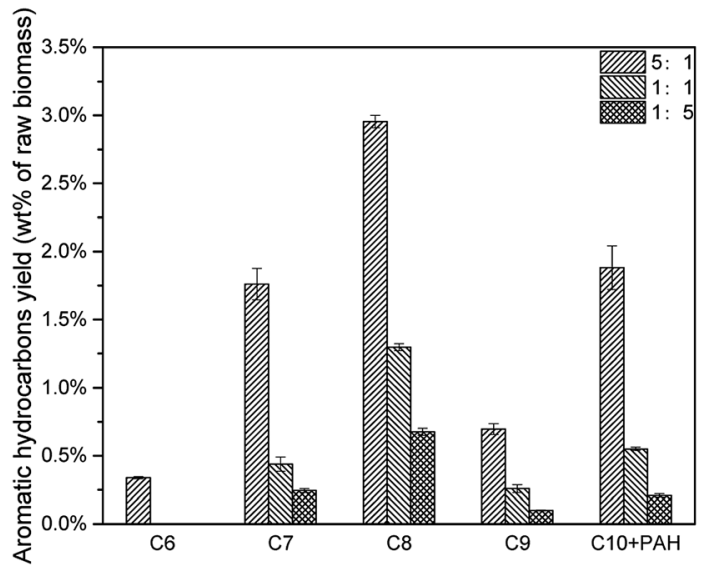

Fig. 11 Aromatic hydrocarbon yields of catalytic pyrolysis with different CLR.

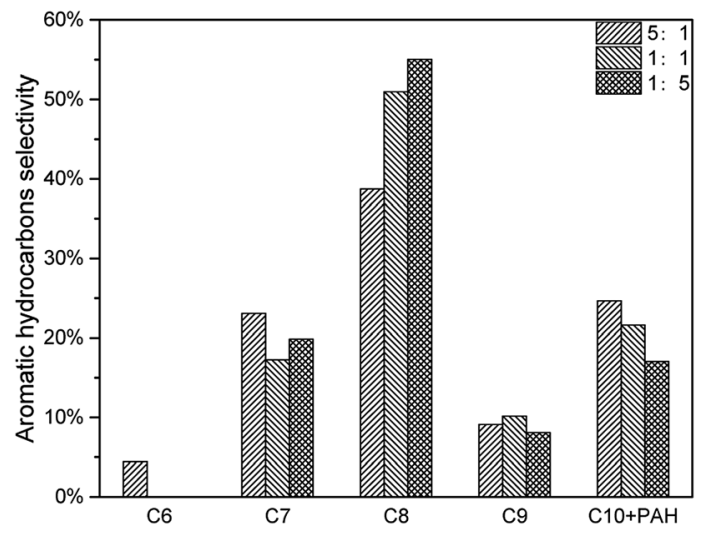

Fig. 12 Aromatic hydrocarbon selectivity of catalytic pyrolysis with different CLR.

more alkanes and alkenes. ${ }^{22}$ However, at $650{ }^{\circ} \mathrm{C}$, C3 (propane, propylene) and $\mathrm{C} 4$ (butane, butylene) achieved the highest yield. When the pyrolysis temperature increased to $700{ }^{\circ} \mathrm{C}$, although the average value of $\mathrm{C} 3$ and $\mathrm{C} 4$ decreased, when considering the standard deviation presented, these values were statistically similar.(Table 6)

The effects of pyrolysis temperature on condensable fractions were shown in Fig. 14. For all C6-C10 aromatic hydrocarbons, the yield increased from $450{ }^{\circ} \mathrm{C}$ to $600{ }^{\circ} \mathrm{C}$, then decreased after $600^{\circ} \mathrm{C}$. As mentioned above, during the catalytic pyrolysis process, lignin was thermally decomposed to produce pyrolysis vapours. With a higher temperature, feedstock was decomposed more severely. Thus more intermediate products

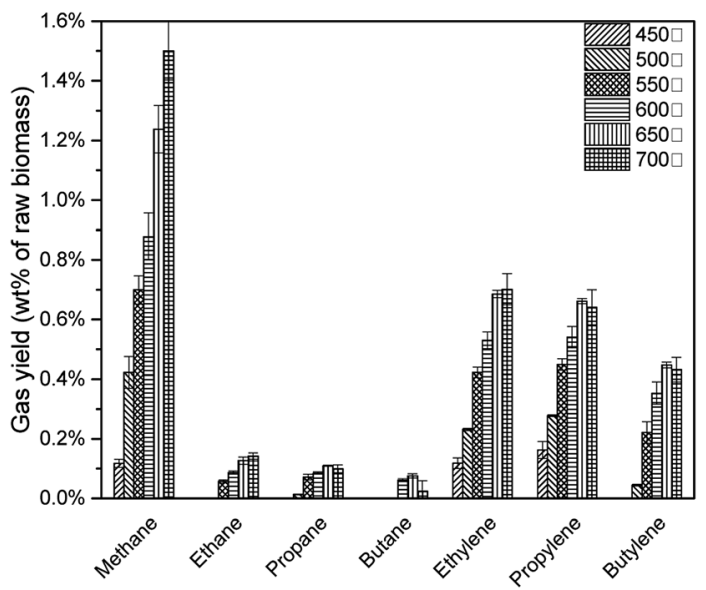

Fig. 13 None-condensable gases from catalytic pyrolysis with different pyrolysis temperature.

Table 6 Hydrocarbon gas yield of catalytic pyrolysis with different pyrolysis temperature

\begin{tabular}{llll}
\hline & $\begin{array}{l}\text { Alkane } \\
\text { yield }\end{array}$ & $\begin{array}{l}\text { Alkene } \\
\text { yield }\end{array}$ & Total \\
\hline $450{ }^{\circ} \mathrm{C}$ & $0.12 \%$ & $0.28 \%$ & $0.40 \%$ \\
$500{ }^{\circ} \mathrm{C}$ & $0.44 \%$ & $0.55 \%$ & $0.99 \%$ \\
$550{ }^{\circ} \mathrm{C}$ & $0.83 \%$ & $1.09 \%$ & $1.92 \%$ \\
$600{ }^{\circ} \mathrm{C}$ & $1.11 \%$ & $1.42 \%$ & $2.54 \%$ \\
$650{ }^{\circ} \mathrm{C}$ & $1.55 \%$ & $1.79 \%$ & $3.34 \%$ \\
$700{ }^{\circ} \mathrm{C}$ & $1.77 \%$ & $1.77 \%$ & $3.54 \%$
\end{tabular}

would take deoxygenation reactions, and more aromatic hydrocarbons would be generated. When the temperature became higher than $600{ }^{\circ} \mathrm{C}$, it would cause the second decomposition reaction of the intermediate products (acid, furan, phenol and sugar) and final products (MAH and $\mathrm{PAH}$ ) to form more coke.(Table 7) However, at $600{ }^{\circ} \mathrm{C}, 7.63 \mathrm{wt} \%$ of aromatic hydrocarbon was produced.(Fig. 15)

3.3.2 Influence of heating rate. In this section, to compare the effect of heating rate, $0.5 \mathrm{mg}$ lignin was mixed with $2.5 \mathrm{mg}$ HZSM-5(23). Then the mixture was pyrolyzed by the Pyroprobe at $600{ }^{\circ} \mathrm{C}$ with different heating rate range from $10-10000 \mathrm{~K} \mathrm{~s}^{-1}$. After achieving $600{ }^{\circ} \mathrm{C}$, the pyrolysis system would be held for $30 \mathrm{~s}$ for reaction.

Previous study illustrated that, a higher heating rate was effective to avoid coke formation as well as increase pyrolysis vapour yield..$^{23}$ Thus, more pyrolysis vapour would be deoxygenated to produce C1-C4 alkanes and alkenes due to HZSM-5

Table 5 Aromatic hydrocarbon yields and selectivity of catalytic pyrolysis with different CLR

\begin{tabular}{llllll}
\hline CLR & MAH yield & PAH yield & Total yield & MAH selectivity & PAH selectivity \\
\hline $5: 1$ & $5.75 \%$ & $1.88 \%$ & $7.63 \%$ & $75.34 \%$ & $24.66 \%$ \\
$1: 1$ & $1.99 \%$ & $0.55 \%$ & $2.54 \%$ & $78.39 \%$ & $21.61 \%$ \\
$1: 5$ & $1.02 \%$ & $0.21 \%$ & $1.23 \%$ & $82.97 \%$ & $17.03 \%$
\end{tabular}




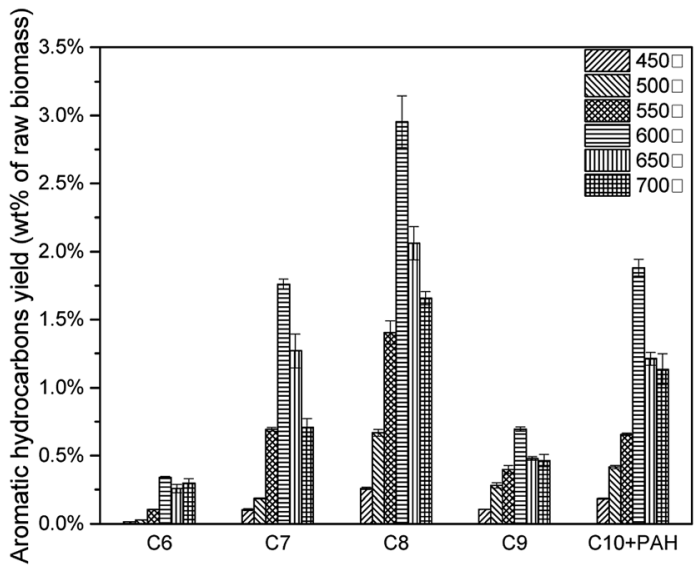

Fig. 14 Aromatic hydrocarbon yields of catalytic pyrolysis with different pyrolysis temperature.

strong acid sites. As shown in Fig. 16, all the alkanes and alkenes increased with a higher heating rate. However, for different heating rate, real resident time was different. Take 10 $\mathrm{K} \mathrm{s}^{-1}$ for example, the Pyroprobe was heated up from $20{ }^{\circ} \mathrm{C}$ (room temperature) to $600{ }^{\circ} \mathrm{C}$, which might be around $58 \mathrm{~s}$. Considering that the system would be held for another $30 \mathrm{~s}$, the whole reaction time was $88 \mathrm{~s}$. For $100 \mathrm{~K} \mathrm{~s}^{-1}$ and $1000 \mathrm{~K} \mathrm{~s}^{-1}$, the real resident time were $35.8 \mathrm{~s}$ and $30.6 \mathrm{~s}$. This might be the reason that the yield for $100 \mathrm{~K} \mathrm{~s}^{-1}$ and $1000 \mathrm{~K} \mathrm{~s}^{-1}$ were similar in Fig. 16.

As mentioned above, higher heating rate resulted in an increase of pyrolysis vapour yield. More pyrolysis vapour generated more $\mathrm{C6}-\mathrm{C} 10$ aromatic hydrocarbon as well as $\mathrm{C} 1-\mathrm{C} 4$ alkanes and alkenes. Results were shown in Fig. 17, for all C6$\mathrm{C} 10$ aromatic hydrocarbon, $10000 \mathrm{~K} \mathrm{~s}^{-1}$ produced the most. The yield of $10 \mathrm{~K} \mathrm{~s}^{-1}, 100 \mathrm{~K} \mathrm{~s}^{-1}$ and $1000 \mathrm{~K} \mathrm{~s}^{-1}$ were similar, which might be influenced by the "real resident time" issue.(Fig. 18, Tables 8 and 9)

\subsection{Reaction pathways to aromatic hydrocarbons over zeolite catalyst}

In order to discuss these different reaction pathways for lignin catalytic pyrolysis, density functional theory were used in this section. 1-(3,5-dimethoxyphenyl)-2-(2-methoxyphenoxy) propane-1,3-diol (DMPD, Fig. 4), a typical $\beta$-o-4 ether linkage lignin dimer, was used as lignin feedstock. ${ }^{20}$ DMPD was decomposed firstly. ${ }^{24}$ Then, C2-C4 dehydrate species would go

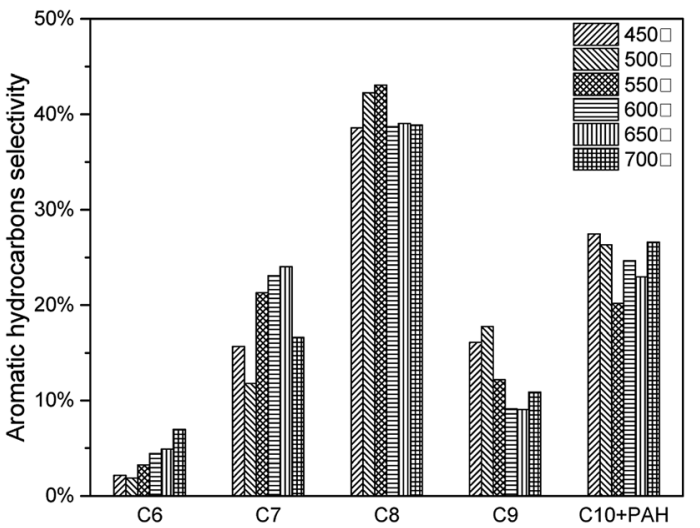

Fig. 15 Aromatic hydrocarbon selectivity of catalytic pyrolysis with different pyrolysis temperature.

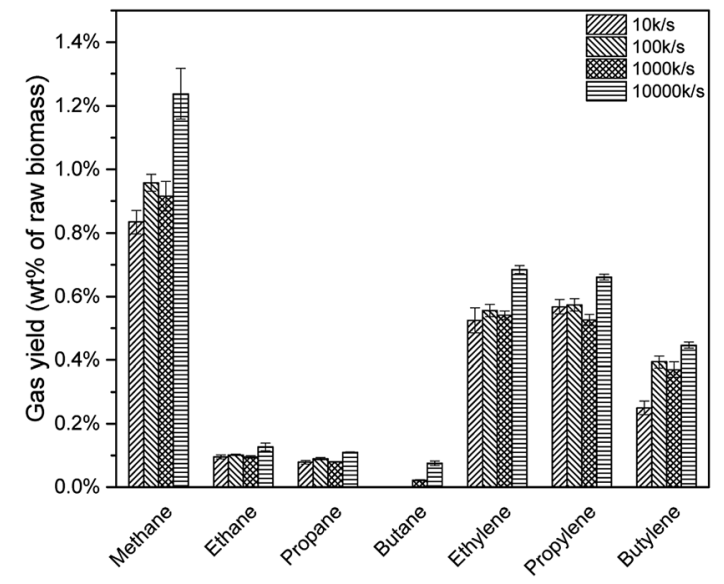

Fig. 16 None-condensable gases from catalytic pyrolysis with different heating rate.

through the olefin to aromatics route, to form the aromatic hydrocarbons (Fig. 19 route 1). On the other hand, after demethylation reaction, demethoxylation reaction and dehydration reaction, 2,6-dimethoxy-4-methylphenol was conversed into xylene (Fig. 19 route 2). Bond dissociation energy (BDE) for each step was shown in Fig. 19. As for route 1, the olefin to aromatics route, the BDEs for each step varied from $93.15 \mathrm{~kJ} \mathrm{~mol}^{-1}$ to $200.06 \mathrm{~kJ} \mathrm{~mol}^{-1}$. As for route $2, \mathrm{BDEs}$ for demethylation reaction, demethoxylation reaction and dehydration reaction were $394.85 \mathrm{~kJ} \mathrm{~mol}^{-1}, 370.63 \mathrm{~kJ} \mathrm{~mol}^{-1}$,

Table 7 Aromatic hydrocarbon yields and selectivity of catalytic pyrolysis with different pyrolysis temperature

\begin{tabular}{|c|c|c|c|c|c|}
\hline Pyrolysis temperature & MAH yield & PAH yield & Total yield & MAH selectivity & PAH selectivity \\
\hline $450{ }^{\circ} \mathrm{C}$ & $0.49 \%$ & $0.18 \%$ & $0.67 \%$ & $72.54 \%$ & $27.46 \%$ \\
\hline $500{ }^{\circ} \mathrm{C}$ & $1.17 \%$ & $0.42 \%$ & $1.58 \%$ & $73.67 \%$ & $26.33 \%$ \\
\hline $550{ }^{\circ} \mathrm{C}$ & $2.60 \%$ & $0.66 \%$ & $3.26 \%$ & $79.82 \%$ & $20.18 \%$ \\
\hline $600{ }^{\circ} \mathrm{C}$ & $5.75 \%$ & $1.88 \%$ & $7.63 \%$ & $75.34 \%$ & $24.66 \%$ \\
\hline $650{ }^{\circ} \mathrm{C}$ & $4.07 \%$ & $1.21 \%$ & $5.28 \%$ & $77.04 \%$ & $22.96 \%$ \\
\hline $700{ }^{\circ} \mathrm{C}$ & $3.13 \%$ & $1.13 \%$ & $4.26 \%$ & $73.37 \%$ & $26.63 \%$ \\
\hline
\end{tabular}




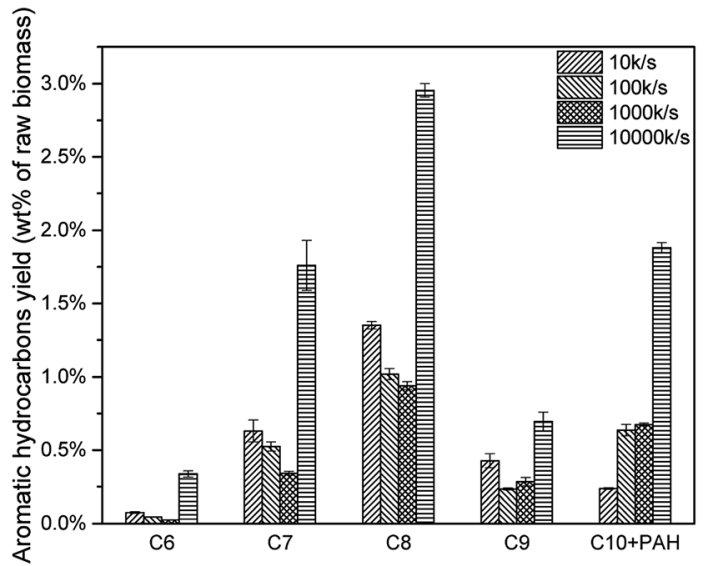

Fig. 17 Aromatic hydrocarbon yields of catalytic pyrolysis with different heating rate.

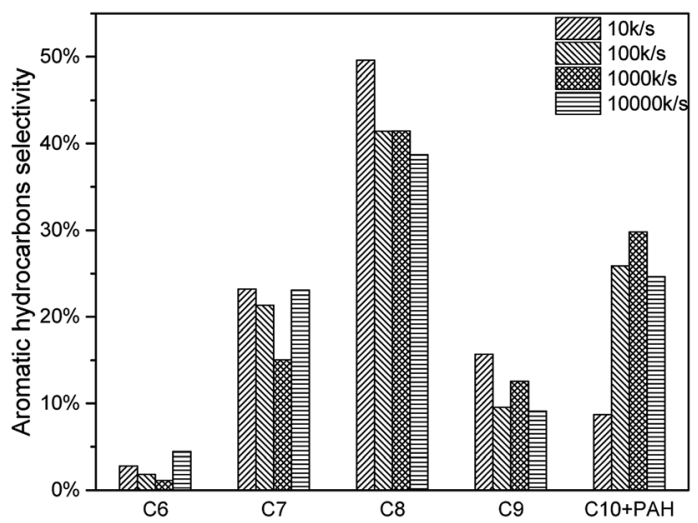

Fig. 18 Aromatic hydrocarbon selectivity of catalytic pyrolysis with different heating rate.

Table 8 Hydrocarbon gas yield of catalytic pyrolysis with different heating rate

\begin{tabular}{llll}
\hline Heating rate & $\begin{array}{l}\text { Alkane } \\
\text { yield }\end{array}$ & $\begin{array}{l}\text { Alkene } \\
\text { yield }\end{array}$ & Total \\
\hline $10 \mathrm{~K} \mathrm{~s}^{-1}$ & $1.01 \%$ & $1.34 \%$ & $2.35 \%$ \\
$100 \mathrm{~K} \mathrm{~s}^{-1}$ & $1.17 \%$ & $1.52 \%$ & $2.69 \%$ \\
$1000 \mathrm{~K} \mathrm{~s}^{-1}$ & $1.09 \%$ & $1.44 \%$ & $2.53 \%$ \\
$10000 \mathrm{~K} \mathrm{~s}^{-1}$ & $1.55 \%$ & $1.79 \%$ & $3.34 \%$
\end{tabular}

$361.09 \mathrm{~kJ} \mathrm{~mol}^{-1}$ and $408.79 \mathrm{~kJ} \mathrm{~mol}^{-1}$, which were significantly higher than route 1 . Comparatively, route 1 was a more favourable reaction pathway than route 2 . However, C2-C4

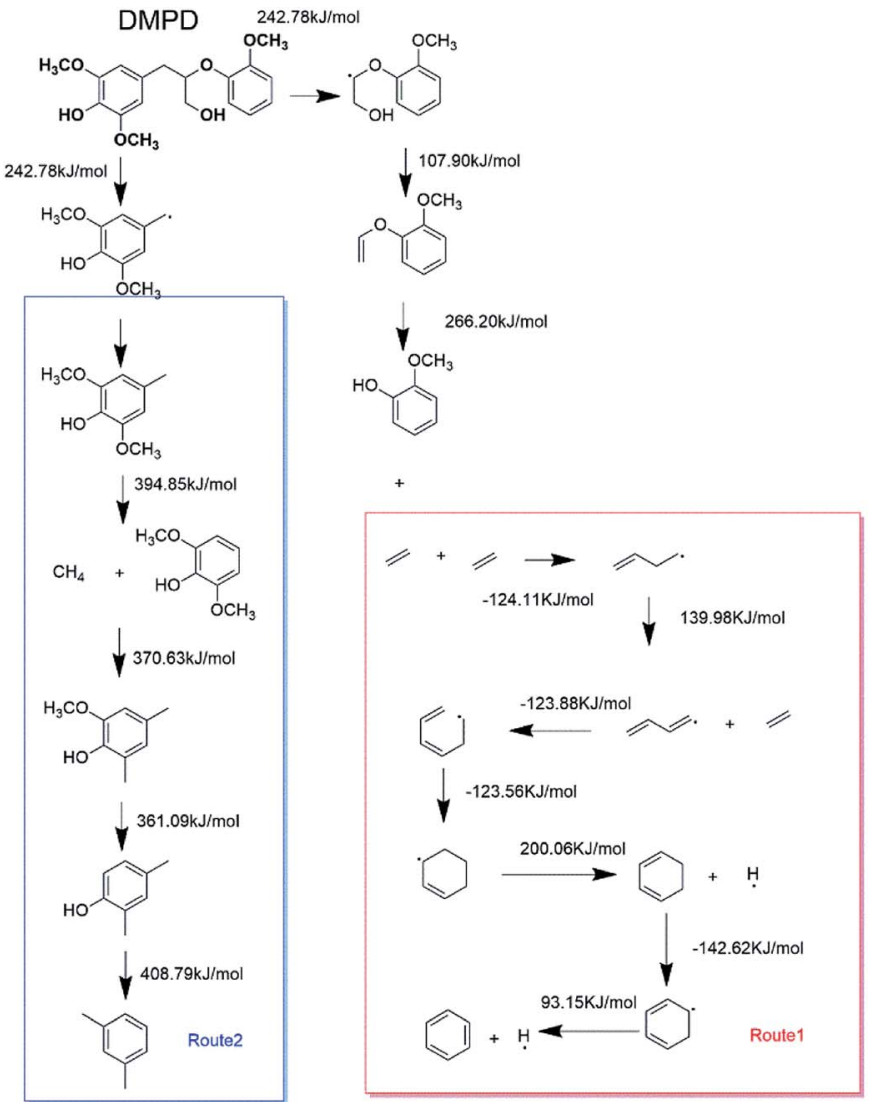

Fig. 19 Bond dissociation energy for different reaction pathways using DFT method.

dehydrate products in route 1 mainly came from substituents of benzene ring. In some cases, $7.63 \mathrm{wt} \%$ of aromatic hydrocarbons and $3.34 \mathrm{wt} \%$ of $\mathrm{C} 1-\mathrm{C} 4$ alkanes and alkenes were acquired. Obviously, route1 alone was not able to produce such amount of hydrocarbon products. Thus, part of the aromatic hydrocarbons were formed via route 2, especially when reaction temperature was higher.

In section 3.1.2 HZSM-5 serious catalysts and $\mathrm{H} \beta$ showed a different products distribution. The pore size of HZSM-5 series catalysts is around $0.5 \mathrm{~nm}$, which is suitable for BTEX (C6, C7, and C8). So, it could be a reasonable speculation that route 1 might be a primary reaction pathway for the pyrolysis vapours with HZSM-5. Consequently, HZSM-5 had a high selectivity in $\mathrm{C} 7$ and $\mathrm{C} 8$ and relatively low selectivity in $\mathrm{C} 9$ (Section 3.1.2 Fig. 9). On the contrary, the pore size of $\mathrm{H} \beta$ is around $0.767 \mathrm{~nm}$, which is suitable not only for BTEX (C6, C7, $\mathrm{C} 8$ ), but also for $\mathrm{C} 9, \mathrm{C} 10$ and some intermediate products in

Table 9 Aromatic hydrocarbon yields and selectivity of catalytic pyrolysis with different heating rate

\begin{tabular}{|c|c|c|c|c|c|}
\hline $10 \mathrm{~K} \mathrm{~s}^{-1}$ & $2.49 \%$ & $0.24 \%$ & $2.72 \%$ & $91.29 \%$ & $8.71 \%$ \\
\hline $100 \mathrm{~K} \mathrm{~s}^{-1}$ & $1.82 \%$ & $0.64 \%$ & $2.46 \%$ & $74.11 \%$ & $25.89 \%$ \\
\hline $10000 \mathrm{~K} \mathrm{~s}^{-1}$ & $5.75 \%$ & $1.88 \%$ & $7.63 \%$ & $75.34 \%$ & $24.66 \%$ \\
\hline
\end{tabular}


route 2 . Thus, there might be more intermediate products taking demethylation reactions, demethoxylation reactions and dehydration reactions in route 2 to produce more aromatic hydrocarbons. This might be the reason that $\mathrm{H} \beta$ had almost the same selectivity for C7, C8, C9, C10 + PAH (Section 3.1.2 Fig. 9).

\section{Conclusions}

Pyrolysis experiment results proved that lignin catalytic fast pyrolysis with HZSM-5, HY, H $\beta$ was a promising way to obtain aromatic hydrocarbons. Among those catalysts, HZSM-5(23) provided the desired acidity and shape selectivity for aromatic hydrocarbon production. Higher CLR and higher heating rate resulted in higher aromatic hydrocarbon yield. $600{ }^{\circ} \mathrm{C}$ was the most suitable pyrolysis temperature for aromatic hydrocarbon production. $7.63 \mathrm{wt} \%$ of aromatic hydrocarbons and $3.34 \mathrm{wt} \%$ of $\mathrm{C} 1-\mathrm{C} 4$ alkanes and alkenes were acquired by lignin catalytic fast pyrolysis.

DFT calculations showed that the BDEs for route 1 (cyclization reactions) were significantly lower than route 2 (demethylation, demethoxylation and dehydration reactions). Route 1 was a more favourable reaction pathway than route 2. Associated with experimental results, route 1 was the primary reaction pathway in catalytic pyrolysis with HZSM-5 series catalysts. As for the catalysts with larger pore size (such as $\mathrm{H} \beta$ ), both route 1 and route 2 were important reaction pathways.

\section{Conflicts of interest}

There are no conflicts to declare.

\section{Acknowledgements}

The authors of this paper gratefully acknowledge the financial support from the National Key R\&D Program of China (2018YFB1501405).

\section{References}

1 T. R. Carlson, G. A. Tompsett, W. C. Conner and G. W. Huber, Top. Catal., 2009, 52, 241-252.

2 Wikipedia, https://en.wikipedia.org/wiki/BTX_(chemistry)).

3 Y. Yang, Z. Luo, W. Chen, G. Li, K. Lu and H. Zhang, Energy Procedia, 2014, 61, 4.
4 C. A. Mullen and A. A. Boateng, Fuel Process. Technol., 2010, 91, 1446-1458.

5 K. Wang, K. H. Kim and R. C. Brown, Green Chem., 2014, 16, 727-735.

6 J.-Y. Kim, J. H. Lee, J. Park, J. K. Kim, D. An, I. K. Song and J. W. Choi, J. Anal. Appl. Pyrolysis, 2015, 114, 273-280.

7 D. J. Nowakowski, A. V. Bridgwater, D. C. Elliott, D. Meier and P. de Wild, J. Anal. Appl. Pyrolysis, 2010, 88, 53-72.

8 H. Ben and A. J. Ragauskas, ACS Sustainable Chem. Eng., 2013, 1, 316-324.

9 T. R. Carlson, T. P. Vispute and G. W. Huber, ChemSusChem, 2008, 1, 397-400.

10 T. R. Carlson, J. Jae and G. W. Huber, ChemCatChem, 2009, 1, 107-110.

11 A. J. Foster, J. Jae, Y.-T. Cheng, G. W. Huber and R. F. Lobo, Appl. Catal., A, 2012, 423-424, 154-161.

12 Y. T. Cheng, Z. Wang, C. J. Gilbert, W. Fan and G. W. Huber, Angew. Chem., Int. Ed. Engl., 2012, 51, 11097-11100.

13 G. Zhou, P. A. Jensen, D. M. Le, N. O. Knudsen and A. D. Jensen, Green Chem., 2016, 18, 1965-1975.

14 Z. Ma, E. Troussard and J. A. van Bokhoven, Appl. Catal., A, 2012, 423-424, 130-136.

15 S. D. Stefanidis, K. G. Kalogiannis, E. F. Iliopoulou, C. M. Michailof, P. A. Pilavachi and A. A. Lappas, J. Anal. Appl. Pyrolysis, 2014, 105, 143-150.

16 H. Yang, R. Yan, H. Chen, D. H. Lee and C. Zheng, Fuel, 2007, 86, 1781-1788.

17 Z. Ma, Q. Sun, J. Ye, Q. Yao and C. Zhao, J. Anal. Appl. Pyrolysis, 2016, 117, 116-124.

18 J. Zhang, Z. Luo, Q. Dang, J. Wang and W. Chen, Energy Fuels, 2012, 26, 2990-2995.

19 Q. Dang, Z. Luo, J. Zhang, J. Wang, W. Chen and Y. Yang, Fuel, 2013, 103, 683-692.

20 S. Wang, B. Ru, G. Dai, Z. Shi, J. Zhou, Z. Luo, M. Ni and K. Cen, Proc. Combust. Inst., 2017, 36, 2225-2233.

21 M. Zhang, F. L. P. Resende and A. Moutsoglou, Fuel, 2014, 116, 358-369.

22 H. W. Lee, Y.-M. Kim, J. Jae, B. H. Sung, S.-C. Jung, S. C. Kim, J.-K. Jeon and Y.-K. Park, J. Anal. Appl. Pyrolysis, 2016, 122, 282-288.

23 P. Giudicianni, G. Cardone and R. Ragucci, J. Anal. Appl. Pyrolysis, 2013, 100, 213-222.

24 C. Li, X. Zhao, A. Wang, G. W. Huber and T. Zhang, Chem. Rev., 2015, 115, 11559-11624. 